\title{
Influence of structural and textural parameters of carbon nanofibers on their capacitive behavior
}

\author{
Adam Moyseowicz $^{1} \cdot$ Agata Śliwak $^{1} \cdot$ Grażyna Gryglewicz $^{1}$
}

Received: 21 July 2015/Accepted: 10 December 2015/Published online: 21 December 2015

(c) The Author(s) 2015. This article is published with open access at Springerlink.com

\begin{abstract}
Herringbone, platelet, and tubular carbon nanofibers (CNFs) were synthesized by catalytic chemical vapor deposition using methane, propane, and ethylene as carbon precursors. Alumina-supported nickel and iron catalysts were used for the syntheses. The resultant CNFs were characterized by scanning electron microscopy, transmission electron microscopy, and nitrogen sorption at $77 \mathrm{~K}$. The performance of a CNF-based supercapacitor working in $6 \mathrm{~mol} \mathrm{~L}^{-1} \mathrm{KOH}$ was analyzed using cyclic voltammetry, galvanostatic charge/discharge, and electrochemical impedance spectroscopy techniques. The Brunauer-Emmett-Teller (BET) surface area of the CNFs ranged between 150 and $296 \mathrm{~m}^{2} \mathrm{~g}^{-1}$. An increase in the CNF diameter was accompanied by a decrease in the BET surface area. A comparison of the porous textures and the structure types of the CNFs demonstrated that the performance of the CNF-based supercapacitor is enhanced primarily by the exposed edges of the graphitic layers on the $\mathrm{CNF}$ surface, followed by the specific surface area. Among the studied CNFs, the highest capacitance value, $26 \mathrm{~F} \mathrm{~g}^{-1}$ at $0.2 \mathrm{~A} \mathrm{~g}^{-1}$, was obtained for the platelet-type CNFs.
\end{abstract}

Electronic supplementary material The online version of this article (doi:10.1007/s10853-015-9660-2) contains supplementary material, which is available to authorized users.

Grażyna Gryglewicz

grazyna.gryglewicz@pwr.edu.pl

Adam Moyseowicz

adam.moyseowicz@pwr.edu.pl

Agata Śliwak

agata.sliwak@pwr.edu.pl

1 Department of Polymer and Carbonaceous Materials, Faculty of Chemistry, Wrocław University of Technology, Gdańska 7/9, 50-344 Wrocław, Poland
Tubular CNFs exhibited the lowest capacitance value, which increased from 4 to $33 \mathrm{~F} \mathrm{~g}^{-1}$ at $0.2 \mathrm{~A} \mathrm{~g}^{-1}$ upon air treatment at $450{ }^{\circ} \mathrm{C}$. The presence of exposed graphitic edges on the air-treated CNT surface and an increase in the specific surface area are considered to be responsible for the enhancement of the capacitor performance.

\section{Introduction}

The increasing demand for electrical devices has stimulated the intensive development of electric double-layer capacitors (EDLCs) and lithium-ion batteries (LiBs), which are used in a wide range of industry and daily life applications [1-3]. Carbon materials, including activated carbons, carbon aerogels, carbon nanofibers (CNFs), and graphene materials, have been extensively investigated for efficient and long-lasting energy storage in EDLCs and LiBs [3-7]. In an EDLC, electrical energy is stored by the electrostatic accumulation of charge in the electric double-layer at the electrode/electrolyte interface, thus making it possible to achieve fast charge-discharge rates and high power values. EDLC performance is strongly related to the electrode material, and can be enhanced by selecting carbons with a high surface area and good electrical conductivity [8]. Generally, the higher the surface area of the carbon material accessible to the electrolyte ion, the higher capacitance value is obtained [913]. However, the capacitance becomes almost constant for carbons with BET surface area higher than $1800 \mathrm{~m}^{2} \mathrm{~g}^{-1}[14,15]$.

CNFs have been reported to form unique nanostructures, depending on the arrangement of the graphene layers along the fiber axis. Typically, three structural types of CNFs are 
distinguished based on the angle of the graphene layers with respect to the fiber axis; herringbone, platelet, and tubular CNFs [16]. It has been widely accepted to describe tubular CNFs with graphene layers parallel to the filament axis as carbon nanotubes (CNTs).

The exceptional physicochemical properties of CNFs, including CNTs, such as a large area of exposed surface for electrolyte ions, high electrical conductivity, and chemical stability, underpin their potential applications for supercapacitors $[1,17]$. However, pure $\mathrm{CNFs} / \mathrm{CNTs}$ as capacitor electrode materials can only supply relatively low capacitance values, i.e., from 5 to $30 \mathrm{~F} \mathrm{~g}^{-1}$, due to their moderate surface area (up to $400 \mathrm{~m}^{2} \mathrm{~g}^{-1}$ ) [18-21]. It has been reported that CNTs with structural defects exhibit the higher gravimetric capacitance than purified and defectfree ones $[18,22]$. The capacitance of CNFs/CNTs can be enhanced through development of their surface area by chemical activation [23] and air treatment [24] or the introduction of oxygen and nitrogen functional groups into their surface to provide pseudocapacitance [25-27]. Their superior conductive properties make CNFs/CNTs very attractive as percolating additives in activated carbonbased electrodes of supercapacitors [28-31], conducting supports of metallic oxides [32,33] and excellent components of carbon/carbon composites [17, 34, 35]. A very high electrical conductivity of $10^{3}-10^{4} \mathrm{~S} \mathrm{~cm}^{-1}$ has been reported for multi-walled CNTs [36].

Kim et al. [18] studied the capacitive behavior of welldefined CNF surfaces. They reported that the capacitance values for CNFs with exposed graphitic edges, such as herringbone and platelet, are several times higher than for tubular CNFs. This finding was explained by more efficient charging of the graphitic edges at the surface of the carbon materials under electrochemical polarization compared with the basal plane surface. Unfortunately, the impact of the specific surface area on the capacitance of CNFs has been omitted. The diameter of CNFs may be another factor influencing the electrochemical performance [18].

The aim of this work was to determine which feature of CNFs has the predominant impact on their capacitive behavior. The interplay of the graphitic alignment, the specific surface area, and the nanofiber diameter in influencing the performance of the CNF-based electrochemical capacitor was discussed. For this purpose, CNFs of various structures (herringbone, platelet, and tubular) were synthesized by the CVD method using different carbon precursors and catalysts. The capacitive behavior of the resulting CNFs was tested in a two-electrode cell by cyclic voltammetry, galvanostatic charging/discharging, and electrochemical impedance spectroscopy (EIS) techniques in $6 \mathrm{~mol} \mathrm{~L}^{-1} \mathrm{KOH}$ as electrolyte.

\section{Experimental}

\section{Preparation of alumina-supported catalysts}

Two catalysts, an alumina-supported nickel catalyst and an alumina-supported iron catalyst, were prepared by the incipient wetness method. Alumina (particle size $<50 \mathrm{~nm}$ ) was obtained from Sigma-Aldrich. The preparation of Ni/ $\mathrm{Al}_{2} \mathrm{O}_{3}$ using an aqueous solution of $\mathrm{Ni}\left(\mathrm{NO}_{3}\right)_{2} \cdot 6 \mathrm{H}_{2} \mathrm{O}$ (Across, $98 \%$ ) was reported in previous work [25]. The $\mathrm{Fe} / \mathrm{Al}_{2} \mathrm{O}_{3}$ catalyst was prepared using an aqueous solution of $\mathrm{Fe}\left(\mathrm{NO}_{3}\right)_{3} \cdot 9 \mathrm{H}_{2} \mathrm{O}$ (Sigma-Aldrich, $98 \%$ ). The amount of $\mathrm{Ni}$ and Fe precursor was adjusted to achieve $10 \mathrm{wt} \%$ of the metal in the catalyst. The as-prepared samples were dried at $110{ }^{\circ} \mathrm{C}$ and subjected to calcination in the air at $350{ }^{\circ} \mathrm{C}$ for $4 \mathrm{~h}$.

\section{CCVD process}

The CNFs of different structures were synthesized by CCVD using $\mathrm{Ni} / \mathrm{Al}_{2} \mathrm{O}_{3}$ and $\mathrm{Fe} / \mathrm{Al}_{2} \mathrm{O}_{3}$ as catalysts and methane, propane, and ethylene as carbon precursors. The herringbone $\mathrm{CNFs}$ were synthesized over $\mathrm{Ni} / \mathrm{Al}_{2} \mathrm{O}_{3}$ catalyst using different carbon sources, i.e., methane (HCNF1) and propane (HCNF2). The same catalyst was applied for the growth of platelet CNFs (PCNF) from propane. The $\mathrm{Fe} /$ $\mathrm{Al}_{2} \mathrm{O}_{3}$ catalyst was used for the synthesis of tubular CNFs with ethylene as a carbon precursor. The CCVD process conditions, including the temperatures of catalyst reduction and CNF synthesis, are given in Table S1. The CCVD processes were performed in a conventional horizontal furnace. Two hundred milligrams of the catalyst was spread in the bottom of a quartz boat and placed in the center of the quartz tube. Prior to the CNF growth, the Ni/ $\mathrm{Al}_{2} \mathrm{O}_{3}$ catalyst was reduced for $2 \mathrm{~h}$ under a hydrogen flow $\left(150 \mathrm{ml} \mathrm{min}^{-1}\right)$ at $550{ }^{\circ} \mathrm{C}$. Subsequently, a mixture of methane and hydrogen at a volume ratio of $1: 1$ $\left(150 \mathrm{ml} \mathrm{min}{ }^{-1}\right)$ was introduced into the reactor for $1 \mathrm{~h}$ at $650{ }^{\circ} \mathrm{C}$ and cooled to room temperature in a nitrogen atmosphere $\left(150 \mathrm{ml} \mathrm{min}^{-1}\right)$. The CCVD processes using propane were performed under the same conditions, including the reduction step, except for the synthesis temperature, which was $500{ }^{\circ} \mathrm{C}$ for $\mathrm{HCNF} 2$ and $450{ }^{\circ} \mathrm{C}$ for PCNF. The synthesis of tubular CNFs (labeled as CNT) was performed using the $\mathrm{Fe} / \mathrm{Al}_{2} \mathrm{O}_{3}$ catalyst without the reduction step. The mixture of $\mathrm{C}_{2} \mathrm{H}_{4}$ and $\mathrm{H}_{2}(1: 3, \mathrm{v} / \mathrm{v}$, $150 \mathrm{ml} \mathrm{min}^{-1}$ ) was introduced into the reactor for $1 \mathrm{~h}$ at $650{ }^{\circ} \mathrm{C}$.

The removal of the catalysts from the as-received CNFs was performed by hydrofluoric acid treatment for $2 \mathrm{~h}$ at room temperature. Then, the CNFs were filtered, washed with distilled water, and finally dried at $110{ }^{\circ} \mathrm{C}$ for $2 \mathrm{~h}$. 


\section{Oxidative treatment}

Tubular CNFs were treated with air $\left(330 \mathrm{ml} \mathrm{min}^{-1}\right)$ in a quartz boat in the horizontal reactor at $450{ }^{\circ} \mathrm{C}(\mathrm{CNT} 450)$ for $1 \mathrm{~h}$. Afterwards, the reactor was cooled to room temperature under a nitrogen flow $\left(150 \mathrm{ml} \mathrm{min}^{-1}\right)$.

\section{CNF characterization}

The CNFs were observed with an EVO LS13 Zeiss scanning electron microscope (SEM). High-resolution transmission electron microscope (HRTEM) images were obtained using a FEI Tecnai $\mathrm{G}^{2}$ 20X-TWIN microscope, operating at an acceleration voltage of $200 \mathrm{kV}$. A few drops of CNF suspension in methanol were dropped onto a copper microgrid with a holy carbon thin film. The diameters of CNFs were estimated by counting about 100 nanofibers on the TEM images. The porous texture characteristics of the materials were determined by $\mathrm{N}_{2}$ sorption at $77 \mathrm{~K}$ by using a NOVA 2000 gas sorption analyzer (Quantachrome). Prior to measurements, the sample was outgassed overnight at $300{ }^{\circ} \mathrm{C}$. The specific surface area $\left(S_{\mathrm{BET}}\right)$ was calculated from the Brunauer-Emmett-Teller (BET) equation. The amount of nitrogen adsorbed at a relative pressure of $p / p_{0}=0.96$ was employed to determine the total pore volume $\left(V_{\mathrm{T}}\right)$. The micropore volume $\left(V_{\mathrm{DR}}\right)$ was estimated from the Dubinin-Radushkevich equation. The mesopore volume $\left(V_{\text {mes }}\right)$ was determined as the difference between the total pore volume and the micropore volume. The pore size distribution (PSD) was obtained by means of the quenched solid density functional theory (QSDFT) method. The elemental compositions of the pristine and air-treated CNTs were determined by X-ray photoelectron spectroscopy (XPS) using a PHI 5000 VersaProbe.

\section{Electrochemical measurements}

The electrodes were composed of $90 \mathrm{wt} \%$ of CNFs and $10 \mathrm{wt} \%$ of polyvinylidene fluoride (PVDF) as a binder. The electrodes were in the form of pellets with a geometric surface area of $0.9 \mathrm{~cm}^{2}$ and a thickness of approximately $0.2 \mathrm{~mm}$. Two-electrode symmetric capacitors were assembled in a Swagelok system with pellets of comparable mass (8-12 mg). The measurements were performed in $6 \mathrm{~mol} \mathrm{~L}{ }^{-1} \mathrm{KOH}$ aqueous solution using gold current collectors to avoid corrosion and to preserve comparable experimental conditions, using a potentiostat-galvanostat VMP3 Biologic in a voltage range of $0.0-0.8 \mathrm{~V}$. The electrochemical properties of CNFs were determined by cyclic voltammetry at a voltage scan rate of $1-100 \mathrm{mV} \mathrm{s}^{-1}$ and galvanostatic cycling at current densities in the range
0.2-20 $\mathrm{A} \mathrm{g}^{-1}$. The specific capacitance was expressed in farads per mass of active material in one electrode. EIS measurements were performed under open circuit potential in a frequency range from $100 \mathrm{kHz}$ to $10 \mathrm{mHz}$ at amplitude of $5 \mathrm{mV}$.

The specific capacitance values $\left(\mathrm{C}, \mathrm{F} \mathrm{g} \mathrm{g}^{-1}\right)$ were calculated from the galvanostatic discharge curves and the $\mathrm{CV}$ curves using Eqs. (1) and (2), respectively.

$C=\frac{I t}{m \Delta V}$

$C=\frac{\left(\int I \mathrm{~d} V\right)}{v m \Delta V}$

where $I(\mathrm{~A})$ is the response current, $t(\mathrm{~s})$ is the discharge time, $v\left(\mathrm{~V} \mathrm{~s}^{-1}\right)$ is the scan rate, $\Delta V(\mathrm{~V})$ is the potential window and $m(\mathrm{~g})$ is the mass of the active material in one electrode.

\section{Results and discussion}

\section{Structure of CNFs}

HRTEM images of the as-grown carbon nanostructures produced by the decomposition of methane, propane, and ethylene over the alumina-supported $\mathrm{Ni}$ and $\mathrm{Fe}$ catalysts are shown in Fig. 1. The CNFs were obtained with a yield in the range of $1.7-5.1 g_{\mathrm{CNF}} / g_{\text {cat }}$ (Table S1). SEM images of the synthesized CNFs are shown in Fig. S1. Various types of CNF structure were obtained depending on the catalyst, synthesis temperature, and carbon source. CNFs with herringbone structure without hollow core were synthesized over nickel catalyst using both methane and propane as carbon precursors, i.e., HCNF1 and HCNF2, respectively (Fig. 1a, b). These CNFs have graphene layers aligned at an angle of less than $90^{\circ}$ to the fiber axis. The diameter of HCNF1 varied from 20 to $60 \mathrm{~nm}$. HCNF2 was characterized by thinner nanofibers with a diameter not exceeding $40 \mathrm{~nm}$. The significant differences in diameter between HCNF1 and HCNF2 are related to the temperature applied for their synthesis. Methane requires a higher temperature than propane due to its higher decomposition energy to carbon and hydrogen $\left(37.8\right.$ and $26.0 \mathrm{~kJ} \mathrm{~mol}^{-1}$ $\mathrm{H}_{2}$ for methane and propane, respectively) [37]. Increased reaction temperatures favor the migration of catalyst particles on the support surface, which results in their aggregation, leading to the growth of thicker CNFs [38]. It is well known that the diameter of nanofibers is controlled by the size of the catalyst particle responsible for their growth [39]. For propane, the decrease in temperature from 500 to $450{ }^{\circ} \mathrm{C}$ led to a change in the $\mathrm{CNF}$ structure from herringbone (HCNF2) to platelet (PCNF), maintaining the same range of $\mathrm{CNF}$ diameters. In the platelet structure, the 

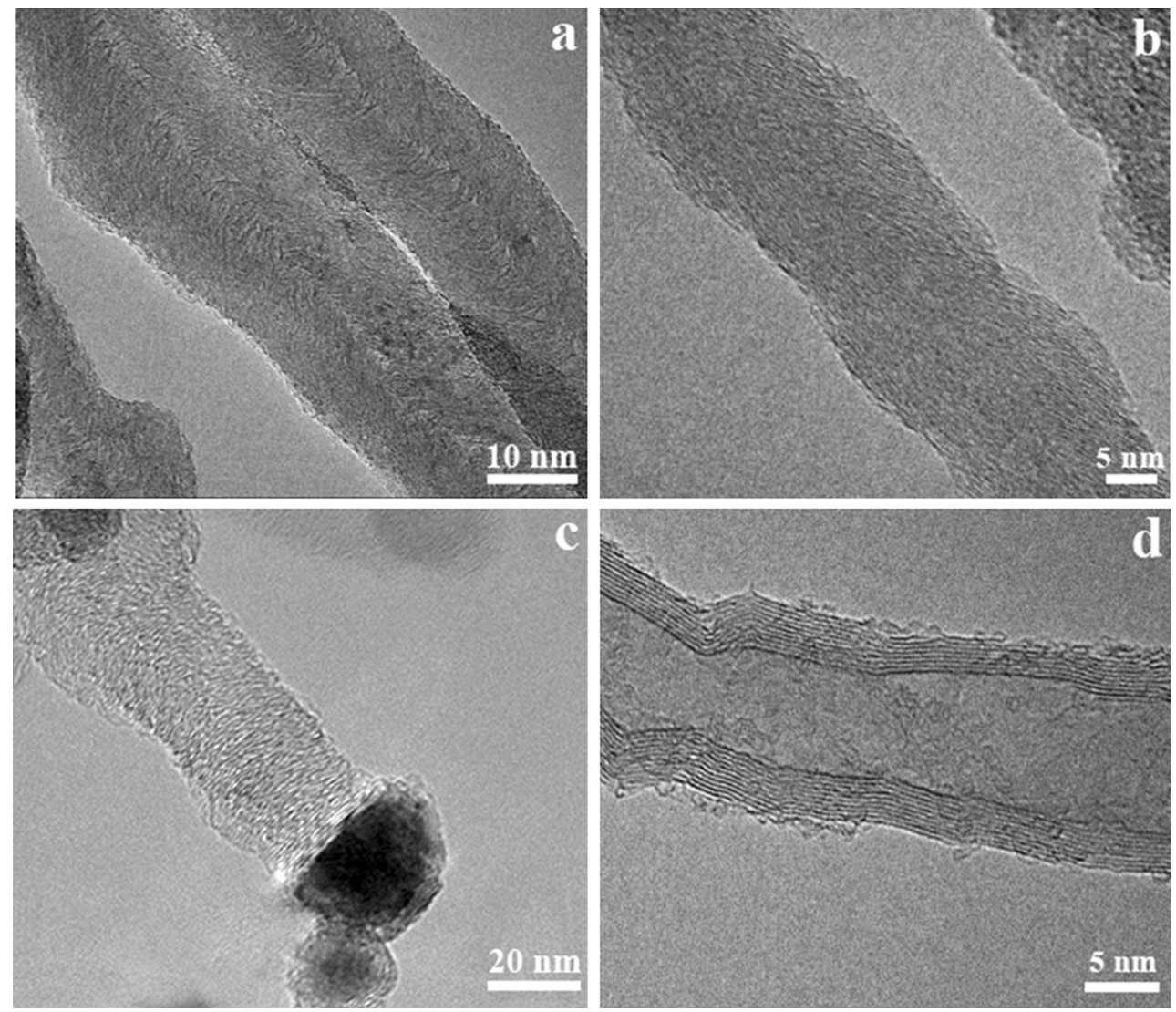

Fig. 1 HRTEM images of the pristine $\operatorname{HCNF} 1$ (a), $\operatorname{HCNF} 2$ (b), PCNF (c), and CNT (d)

graphene layers are aligned perpendicularly to the fiber axis (Fig. 1c). Our study clearly showed that both the diameter and the structure of grown CNFs are strongly dependent on the temperature of the CCVD process. The synthesis temperature has an indirect influence on the $\mathrm{CNF}$ structure through various diffusion rates of carbon into the catalyst particles and different orientations of the graphene layers precipitated on the metal nanoparticle [38]. The CNTs obtained over $\mathrm{Fe} / \mathrm{Al}_{2} \mathrm{O}_{3}$ catalyst using ethylene as a carbon source were the thinnest among the synthesized nanocarbons, with diameters of $10-20 \mathrm{~nm}$, Fig. 1d. A residual amount of amorphous carbon was observed on the CNT surface. The parallel orientation of the graphene layers and the lower diameter arose from the changes to the catalyst and the carbon precursor. The use of an iron catalyst promotes the growth of CNTs, whereas nickel favors the formation of herringbone CNFs [40, 41].

\section{Porous texture of CNFs}

Considering the strong relationship between the porosity development of active electrode material and the amount of charge accumulated in the electric-double layer, the porous texture of CNFs was determined by $\mathrm{N}_{2}$ sorption at $77 \mathrm{~K}$.
Figure $2 \mathrm{a}$ shows the nitrogen adsorption-desorption isotherms for synthesized CNFs. The calculated textural parameters are given in Table 1. The diameters of CNFs estimated based on the TEM examination are also included. The presence of a large hysteresis loop on the adsorption-desorption isotherms for all studied nanocarbons reveals their mesoporous nature. This feature is clearly displayed in the PSD curves (Fig. 2b). It was revealed that all $\mathrm{CNF} / \mathrm{CNTs}$ samples contained mesopores with a width $<20 \mathrm{~nm}$. The CNFs, including CNTs, had BET surface areas between 150 and $296 \mathrm{~m}^{2} \mathrm{~g}^{-1}$ (Table 1). The total pore volume varied from 0.417 to $0.805 \mathrm{~cm}^{3} \mathrm{~g}^{-1}$ with a mesopore contribution of $0.77-0.88$. It was revealed that the differences in the textural parameters are related to the diameter of the CNFs. HCNF1 was characterized by the largest diameters, ranging from 20 to $60 \mathrm{~nm}$, and the lowest development of porosity among the studied nanocarbons. In the case of CNFs with the same structure type but smaller diameter (HCNF2), increased porosity development was observed. The BET surface area of HCNF1 was substantially higher than for HCNF2 (223 and $150 \mathrm{~m}^{2} \mathrm{~g}^{-1}$, respectively). PCNF, which was characterized by a diameter comparable to HCNF2, exhibited a slightly higher specific surface area $\left(251 \mathrm{~m}^{2} \mathrm{~g}^{-1}\right.$ for PCNF and 
Fig. 2 Adsorption-desorption isotherms of nitrogen at $77 \mathrm{~K}$ (a) and QSDFT pore size distribution curves $(\mathbf{b})$ of synthesized CNFs and CNTs
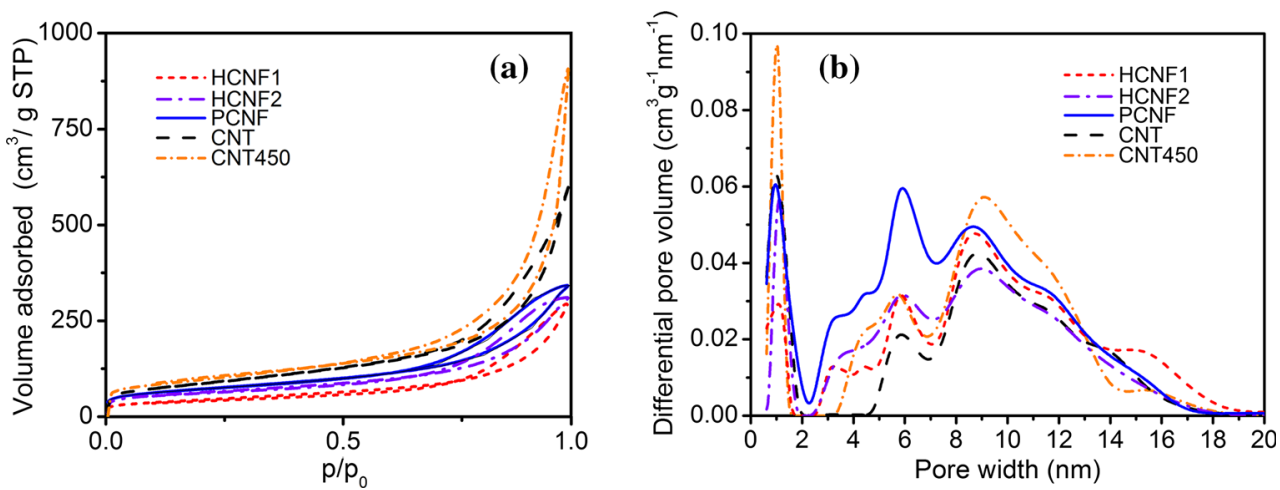

Table 1 Porous texture characteristics of CNFs and CNTs determined by $\mathrm{N}_{2}$ sorption at $77 \mathrm{~K}$

\begin{tabular}{lcllll}
\hline Sample & CNF diameter $(\mathrm{nm})$ & $S_{\text {BET }}\left(\mathrm{m}^{2} \mathrm{~g}^{-1}\right)$ & $V_{\mathrm{T}}\left(\mathrm{cm}^{3} \mathrm{~g}^{-1}\right)$ & $V_{\text {mes }}\left(\mathrm{cm}^{3} \mathrm{~g}^{-1}\right)$ & $V_{\mathrm{DR}}\left(\mathrm{cm}^{3} \mathrm{~g}^{-1}\right)$ \\
\hline HCNF1 & $20-60$ & 150 & 0.417 & 0.366 & 0.051 \\
HCNF2 & $15-40$ & 223 & 0.442 & 0.359 & 0.083 \\
PCNF & $20-40$ & 251 & 0.486 & 0.398 & 0.088 \\
CNT & $10-20$ & 296 & 0.805 & 0.691 & 0.114 \\
CNT450 & $<20$ & 380 & 0.918 & 0.773 & 0.145 \\
\hline
\end{tabular}

$223 \mathrm{~m}^{2} \mathrm{~g}^{-1}$ for $\mathrm{HCNF} 2$, respectively). The difference in the BET surface area between PCNF and HCNF2 could be explained by their different roughness of the outer surface due to structural defects and imperfections on the surface of the nanofibers [42, 43]. However, TEM observation does not provide a clear evidence for this finding. The values of other textural parameters of PCNF were also higher than for HCNF2. CNT was characterized by both the highest BET surface area $\left(296 \mathrm{~m}^{2} \mathrm{~g}^{-1}\right)$ and total pore volume $\left(0.805 \mathrm{~cm}^{3} \mathrm{~g}^{-1}\right)$ and the smallest diameter (approximately 10-20 nm) among the synthesized carbon nanomaterials. The results clearly show a tendency of increasing porosity development with decreasing CNF diameters.

\section{CNF performance in capacitors}

Figure 3 shows the voltammograms of CNFs recorded using a two-electrode cell at different scan rates in
$6 \mathrm{~mol} \mathrm{~L}^{-1} \mathrm{KOH}$. At a scan rate of $10 \mathrm{mV} \mathrm{s}^{-1}$, the CV curves were close to a rectangular shape, indicating an ideal capacitor behavior, including quick charge propagation and fast charge/discharge kinetics (Fig. 3a). Excellent charge propagation in an electrical double layer was observed for all samples, even at the higher scan rate of $100 \mathrm{mV} \mathrm{s}^{-1}$ (Fig. 3b). This result confirms that CNFs exhibit very good electrical conductivity properties. However, the capacitance values were relatively low, ranging from 4 to $26 \mathrm{~F} \mathrm{~g}^{-1}$ at $10 \mathrm{mV} \mathrm{s}^{-1}$ and from 3 to $22 \mathrm{~F} \mathrm{~g}^{-1}$ at $100 \mathrm{mV} \mathrm{s}^{-1}$, due to the poorly developed surface area of the CNFs. The lowest values were obtained for tubular CNFs despite their having the most developed surface area among the studied nanomaterials. The capacitance of the CNF-based capacitors increased in the sequence: $\mathrm{CNT}<\mathrm{HCNF} 1<\mathrm{HCNF} 2<\mathrm{PCNF}$. Notably, considerably higher values were recorded for herringbone and platelet CNFs, with open graphitic edges on their surface,
Fig. 3 Cyclic voltammograms of CNFs recorded in $6 \mathrm{~mol} \mathrm{~L}^{-1}$ $\mathrm{KOH}$ at scan rates of $10 \mathrm{mV} \mathrm{s}^{-1}$ (a) and $100 \mathrm{mV} \mathrm{s}^{-1}$ (b)
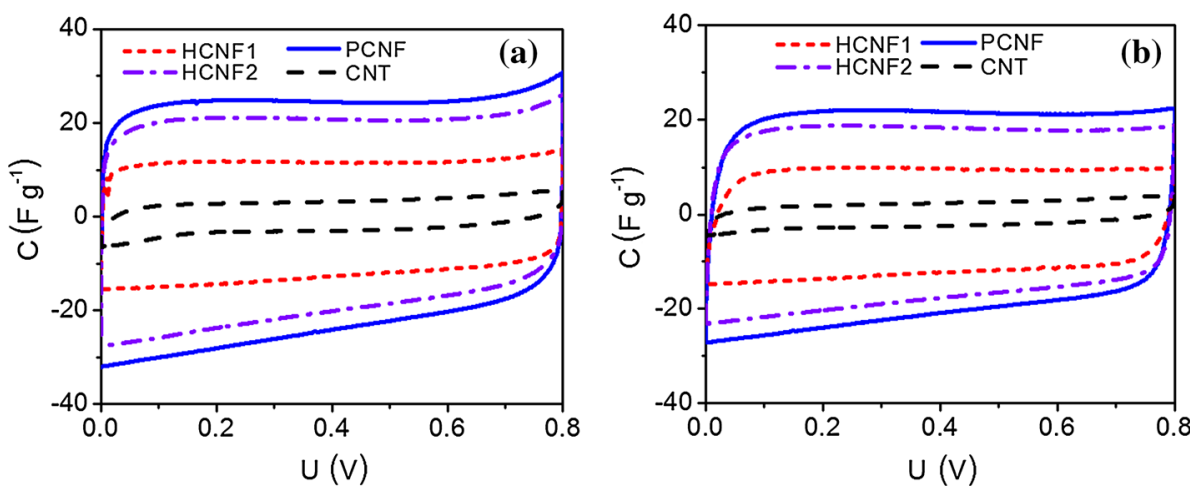
compared to the tubular type, for which the basal planes are exposed to electrolyte ions. The results obtained are in line with the finding of Kim et al. [18] that the edge surfaces of CNFs promote charge storage. Kim et al. synthesized also a series of CNFs with different graphitic layers alignment. Moreover, platelet CNFs were subjected to graphitization at $2800{ }^{\circ} \mathrm{C}$, which resulted in the closure of opened graphitic edges and formation of domelike basal planes. Lower capacitance values were reported for both tubular $\mathrm{CNF}$ and graphitized PCNF compared with herringboneand platelet-type CNFs. In our work, we have also revealed that an increase in the BET surface area of CNFs was not followed by an increase in the capacitance value, highlighting the importance of the structural alignment of the graphene layers in the nanostructured carbon materials.

For the further characterization of CNF-based capacitors, galvanostatic charging/discharging was applied in the range of a current density between 0.2 and $20 \mathrm{~A} \mathrm{~g}^{-1}$. The variations in the capacitance value with increasing current load for the tested samples in two-electrode cells are presented in Fig. 4. The galvanostatic measurements confirmed the tendency shown by cyclic voltammetry. The capacitance value ranged from 4 for $\mathrm{CNT}$ to $26 \mathrm{~F} \mathrm{~g}^{-1}$ for PCNF at $0.2 \mathrm{~A} \mathrm{~g}^{-1}$. PCNF and HCNF2 exhibited superior capacitive performance ( 26 and $21 \mathrm{~F} \mathrm{~g}^{-1}$ at $0.2 \mathrm{~A} \mathrm{~g}^{-1}$ and 21 and $18 \mathrm{~F} \mathrm{~g}^{-1}$ at $1 \mathrm{~A} \mathrm{~g}^{-1}$, respectively) compared with HCNF1 and CNT. The higher capacitances of PCNF and HCNF2 are attributed to porosity development (251 and $223 \mathrm{~m}^{2} \mathrm{~g}^{-1}$, respectively). HCNF1 exhibited lower capacitance values $\left(20\right.$ at $0.2 \mathrm{~A} \mathrm{~g}^{-1}$ and $11 \mathrm{~F} \mathrm{~g}^{-1}$ at $\left.1 \mathrm{~A} \mathrm{~g}^{-1}\right)$ because of its lower surface area $\left(150 \mathrm{~m}^{2} \mathrm{~g}^{-1}\right)$ as consequence of the wider nanofiber diameters. The worst capacitive behavior was again demonstrated by CNT. Although CNT had a larger specific surface area than PCNF (296 vs. $251 \mathrm{~m}^{2} \mathrm{~g}^{-1}$ ), its electrical charge storage capability was limited $\left(4\right.$ vs. $\left.26 \mathrm{~F} \mathrm{~g}^{-1}\right)$. This result is probably related to the exposure of the basal plane surface to electrolyte ions, which is more favorable for conducting

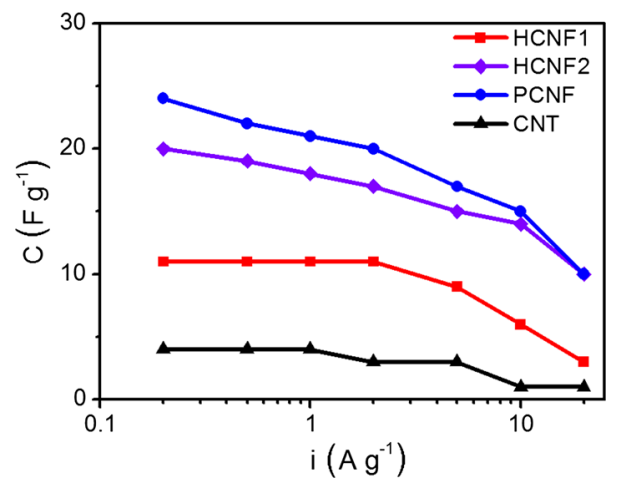

Fig. 4 Specific capacitance versus current load for the CNF-based capacitors working in $6 \mathrm{~mol} \mathrm{~L}^{-1} \mathrm{KOH}$ electrons than for accumulating them. The results suggest that the capacitance of CNFs is controlled more by their surface structure than by their specific surface area.

The impedance spectroscopy (EIS) technique was employed to assess the electrochemical frequency behavior of CNF-based electrodes. Figure 5 shows Nyquist plots for the CNFs measured in the range of $0.01-100 \mathrm{kHz}$ in a twoelectrode cell. Nyquist plots are commonly used to analyze EIS data and reflect conductive properties of carbons. The equivalent series resistance (ESR) determined from the $Z$ ' axis intercept of the Nyquist plot was found to be comparable for all CNFs $(0.31-0.61 \Omega)$; this is a combinational resistance of electrode materials, electrolyte and contact at the active material/current collector interface. A nearly vertical line at low-frequency region observed for all the studied materials indicates a very good diffusion at the interface between the electrolyte and electro-active material, confirming their excellent conductive properties [44]. However, the Nyquist plots at high-frequency region revealed a substantial difference in the behavior between CNFs with open graphitic edges and CNT. In contrast to CNT, a semicircle is observed for a platelet and herringbone CNF-based electrode, which indicates a higher interfacial electron-transfer resistance, probably because of exposed graphitic edges. A low interfacial electron-transfer resistance observed for the CNT-based electrode favors the capacitance retention at high current densities. An increase of the current load from 10 to $20 \mathrm{~A} \mathrm{~g}^{-1}$ resulted in a drop of the capacitance value by only $8 \%$ for CNT, but much more for HCNF2 (29\%), PCNF (33\%), and HCNF1 $(50 \%)$.

Our preliminary study showed a good linear correlation between the capacitance and the BET surface area for CNFs with exposed graphene layer edges in their structure,

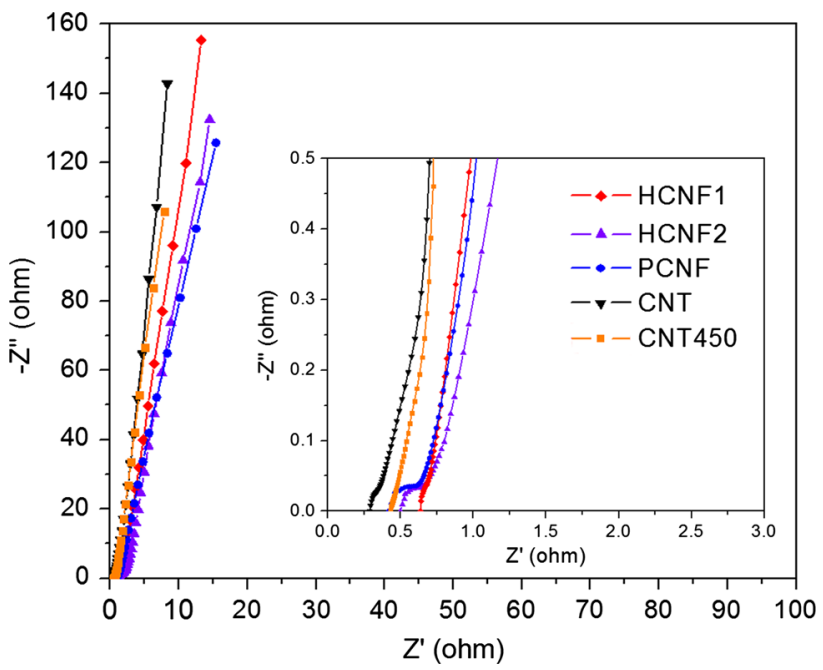

Fig. 5 Nyquist plots of different CNFs measured in a two-electrode cell in $6 \mathrm{~mol} \mathrm{~L}^{-1} \mathrm{KOH}$ solution. The inset shows the expanded highfrequency region of the plots 
i.e., herringbone and platelet CNFs (Fig. S2). Nevertheless, this relationship should be supported by the examination of more CNF samples. No such relationship was observed by for CNFs produced from methane and acetylene on an alumina-supported nickel catalyst [19].

\section{Air treatment of CNT}

CNT was heated with air at $450{ }^{\circ} \mathrm{C}$ to remove residual amorphous carbon from the surface. A weight loss of $3.6 \mathrm{wt} \%$ was observed during air treatment. HRTEM examination indicated that the external graphene layers of CNT450 were slightly deformed and even interrupted, although the core structure remained unchanged (Fig. 6a). Moreover, the air treatment resulted in a noticeable reduction in the diameter of the air-treated CNT. The BET surface area increased from 296 to $380 \mathrm{~m}^{2} \mathrm{~g}^{-1}$ due to air treatment. Both HRTEM and PSD results obtained for the air-treated CNFs explain their enhanced micro- and mesoporosity compared with the pristine CNTs, which is due to opening of basal external graphene layers and following reduction of nanofiber diameters during air treatment (Table 1; Fig. 2b).

The results of electrochemical measurements showed better capacitance behavior for air-treated CNT than pristine CNT (Fig. 6b, c). The almost ideal rectangular shape of the CV curve confirms the very good conductivity properties of the air-treated CNT despite some defects in the external basal planes. At a scan rate of $10 \mathrm{mV} \mathrm{s}^{-1}$, the capacitance value of CNT increased from 4 to $30 \mathrm{~F} \mathrm{~g}^{-1}$ for CNT450, Fig. 6b. Moreover, at a much higher scan rate of $100 \mathrm{mV} \mathrm{s}^{-1}$, the capacitance behavior of CNT450 remained nearly unchanged with very good charge propagation, Fig. 6c. The results of galvanostatic charge/discharge measurements demonstrated a similar tendency to the results of cyclic voltammetry, Fig. 6d. Moreover, the comparison of the EIS spectra for CNT and CNT450 samples (Fig. 5) could suggest an insignificant impact of air treatment on the conductive properties of CNT. The results of the HRTEM examination of CNT450 support this finding, revealing only a small imperfection on the external surface and preserved core structure. It should be added that the contribution of oxygen functional groups to the overall capacitance, due to pseudo-faradaic redox reactions, can be neglected. The XPS analysis revealed that the oxygen content in CNT450 was very low, equal 2.4 at\% (Fig. S3). Therefore, the enhancement of the capacitance properties of the air-treated CNT compared with pristine CNT can be explained by the larger BET surface area and the graphitic edges exposed on the nanofiber surface where the electric charge can be stored.

\section{Conclusions}

Various structure types of CNFs with different porous textures and nanofiber diameters were successfully synthesized by the CCVD method. The study revealed that the
Fig. 6 HRTEM image of CNT air-treated at $450{ }^{\circ} \mathrm{C}(\mathbf{a})$. Deformation of the external graphene layers is indicated by a circle. Cyclic voltammograms of CNT and air-treated CNT capacitors operating in $6 \mathrm{~mol} \mathrm{~L}^{-1} \mathrm{KOH}$ at scan rates of $10 \mathrm{mV} \mathrm{s}^{-1}$ (b) and $100 \mathrm{mV} \mathrm{s}^{-1}$ (c) and specific capacitance versus current load (d) in twoelectrode cells
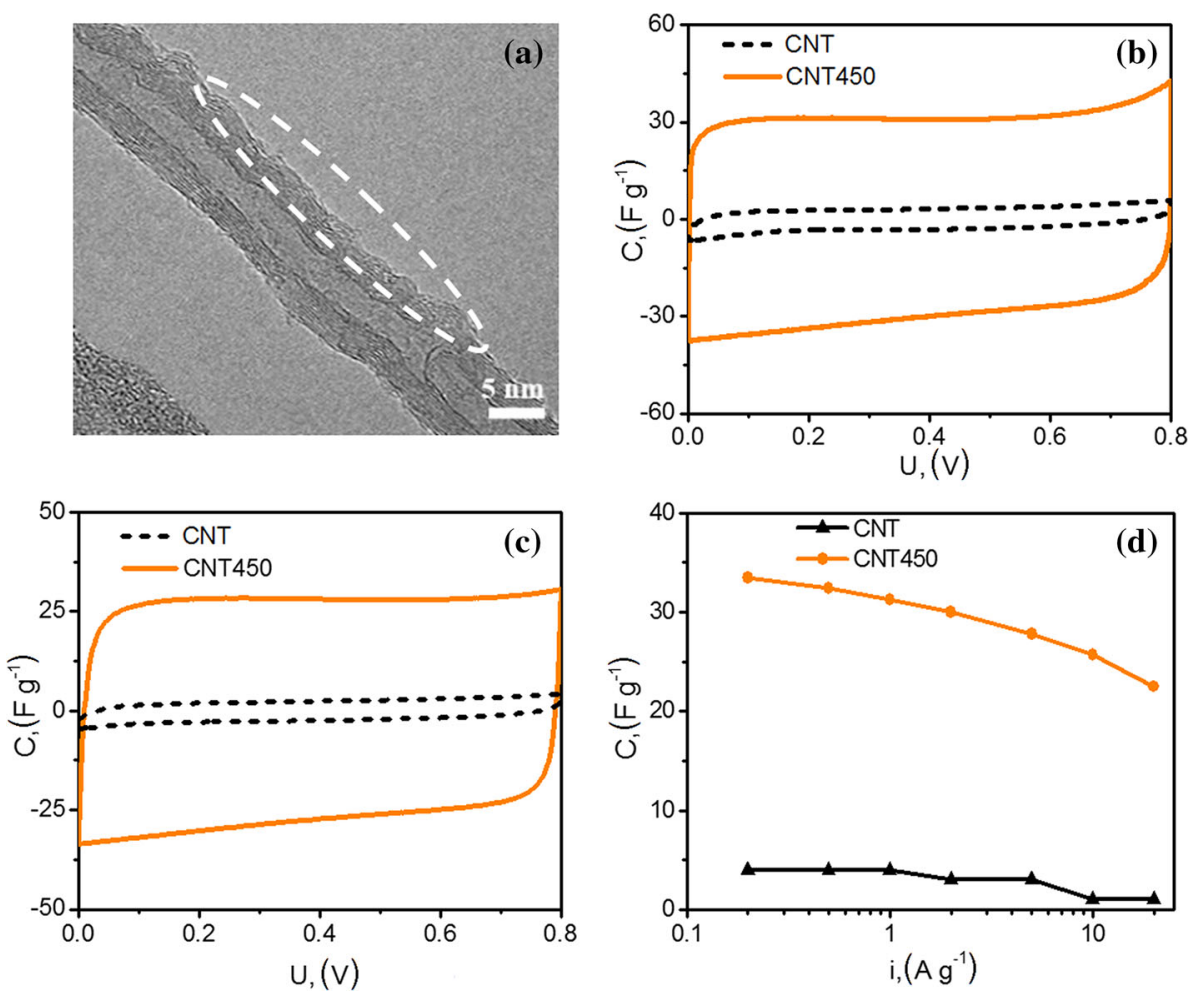
capacitance of CNFs is related to their BET surface area and the alignment of graphitic layers. Moreover, an increase in porosity development with decreasing CNF diameter was observed. The platelet CNFs were characterized by the highest capacitance values $\left(26 \mathrm{~F} \mathrm{~g}^{-1}\right.$ at $\left.0.2 \mathrm{~A} \mathrm{~g}^{-1}\right)$, though not the highest surface area, among the studied nanostructured carbon materials. In turn, despite the most developed surface area, CNT exhibited the lowest capacitance values $\left(4 \mathrm{~F} \mathrm{~g}^{-1}\right.$ at $\left.0.2 \mathrm{~A} \mathrm{~g}^{-1}\right)$. The results clearly showed that exposed graphitic layer edges are beneficial for charge accumulation in an EDLC. This finding was confirmed by the enhanced capacitance of airtreated CNT as a result of the formation of structural defects on the surface during oxidative treatment, which was accompanied by an increase in the BET surface area. The obtained results prove that the capacitance of CNFs is determined by both the graphene layer alignment and the specific surface area, the latter being related to the CNF diameter. This result suggests that the performance of CNF-based capacitors can be improved by using thinner CNFs with exposed graphitic edges on their surface.

Acknowledgements This work was financed by a statutory activity subsidy from the Polish Ministry of Science and Higher Education for the Faculty of Chemistry of Wrocław University of Technology.

Open Access This article is distributed under the terms of the Creative Commons Attribution 4.0 International License (http://crea tivecommons.org/licenses/by/4.0/), which permits unrestricted use, distribution, and reproduction in any medium, provided you give appropriate credit to the original author(s) and the source, provide a link to the Creative Commons license, and indicate if changes were made.

\section{References}

1. Inagaki M, Konno H, Tanaike O (2010) Carbon materials for electrochemical capacitors. J Power Sources 195:7880-7903

2. Pandolfo AG, Hollenkamp AF (2006) Carbon properties and their role in supercapacitors. J Power Sources 157:11-27

3. Zhong H, Xu F, Li Z, Fu R, Wu D (2013) High-energy supercapacitors based on hierarchical porous carbon with an ultrahigh ion-accessible surface area in ionic liquid electrolyte. Nanoscale 5:4678-4682

4. Goriparti S, Miele E, De Angelis F, Di Fabrizio E, Zaccaria RP, Capiglia C (2014) Review on recent progress of nanostructured anode materials for Li-ion batteries. $\mathrm{J}$ Power Sources 257:421-443

5. Yang X, Huang H, Li Z, Zhong M, Zhang G, Wu D (2014) Preparation and lithium-storage performance of carbon/silica composite with a unique porous bicontinous nanostructure. Carbon $77: 257-280$

6. Yang X, Huang H, Zhang G, Li X, Wu D, Fu R (2015) Carbon aerogel with 3-D continuous skeleton and mesopore structure for lithium-ion batteries application. Mater Chem Phys 149-150: 657-662

7. Choi H, Yoon H (2015) Nanostructured electrode materials for electrochemical capacitor applications. Nanomater 5:906-936
8. Frackowiak E, Beguin F (2001) Carbon materials for the electrochemical storage of energy in capacitors. Carbon 39:937-950

9. Shi H (1996) Activated carbons and double layer capacitance. Electrochim Acta 41:1633-1639

10. Lozano-Castello D, Cazorla-Amoros D, Linares-Solano A, Shiraishi S, Kurihara H, Oya A (2003) Influence of pore structure and surface chemistry on electric double layer capacitance in non-aqueous electrolyte. Carbon 41:1765-1775

11. Gryglewicz G, Machnikowski J, Lorenc-Grabowska E, Lota G, Frackowiak E (2005) Effect of pore size distribution of coalbased activated carbons on double layer capacitance. Electrochim Acta 50:1197-1206

12. Fernández JA, Tennison S, Kozynchenko O, Rubiera F, Stoeckli F, Centeno TA (2009) Effect of mesoporosity on specific capacitance of carbons. Carbon 47:1598-1604

13. Yang W, Feng Y, Xiao D, Yuan H (2015) Fabrication of microporous and mesoporous carbon spheres for high-performance supercapacitor electrode materials. Int J Energy Res. doi:10.1002/er.3301

14. Raymundo-Piñero E, Kierzek K, Machnikowski J, Béguin F (2006) Relationship between the nanoporous texture of activated carbons and their capacitance properties in different electrolytes. Carbon 44:2498-2507

15. Barbieri O, Hahn M, Herzog A, Kötz R (2005) Capacitance limits of high surface area activated carbons for double layer capacitors. Carbon 43:1303-1310

16. Rodriguez NM, Chambers A, Baker RTK (1995) Catalytic engineering of carbon nanostructures. Langmuir 11:3862-3866

17. Lota G, Fic K, Frackowiak E (2011) Carbon nanotubes and their composites in electrochemical applications. Energy Environ Sci 4:1592-1605

18. Kim T, Lim S, Kwon K, Hong SH, Qiao W, Rhee CK et al (2006) Electrochemical capacitances of well-defined carbon surfaces. Langmuir 22:9086-9088

19. Hulicova-Jurcakova D, Li X, Zhu Z, de Marco R, Lu GQ (2008) Graphitic carbon nanofibers synthesized by the chemical vapor deposition (CVD) method and their electrochemical performances in supercapacitors. Energy Fuels 22:4139-4145

20. Portet C, Yushin G, Gogotsi Y (2007) Electrochemical performance of carbon onions, nanodiamonds, carbon black and multiwalled nanotubes in electrical double layer capacitors. Carbon 45:2511-2518

21. McDonough JR, Choi JW, Yang Y, La Mantia F, Zhang Y, Cui Y (2009) Carbon nanofiber supercapacitors with large areal capacitances. Appl Phys Lett 95:243109

22. Frackowiak E, Jurewicz K, Delpeux S, Beguin F (2001) Nanotubular materials for supercapacitors. J Power Sources 97-98:822-825

23. Frackowiak E, Delpeux S, Jurewicz K, Szostak K, CazorlaAmoros D, Béguin F (2002) Enhanced capacitance of carbon nanotubes through chemical activation. Chem Phys Lett 361:35-41

24. Seo M-K, Park S-J (2010) Influence of air-oxidation on electric double layer capacitances of multi-walled carbon nanotubes electrodes. Curr Appl Phys 10:241-244

25. Śliwak A, Grzyb B, Ćwikła J, Gryglewicz G (2013) Influence of wet oxidation of herringbone carbon nanofibers on the pseudocapacitance effect. Carbon 64:324-333

26. Ye J-S, Liu X, Cui HF, Zhang W-D, Sheu F-S, Lim TM (2005) Electrochemical oxidation of multi-walled carbon nanotubes and its application to electrochemical double layer capacitors. Electrochem Commun 7:249-255

27. Jurewicz A, Babeł K, Pietrzak R, Delpeux S, Wachowska H (2006) Capacitance properties of multi-walled carbon nanotubes modified by activation and ammoxidation. Carbon 44:2368-2375 
28. Portet C, Taberna PL, Simon P, Flahaut E (2005) Influence of carbon nanotubes addition on carbon-carbon supercapacitor performances in organic electrolyte. J Power Sources 139:371-378

29. Gryglewicz G, Śliwak A, Béguin F (2013) Carbon nanofibers grafted on activated carbon as an electrode in high-power supercapacitors. ChemSusChem 6:1516-1522

30. Huang N, Kirk DW, Thorpe SJ, Liang C, Xu L, Li W et al (2015) Effect of carbon nanotube loadings on supercapacitor characteristics. Int J Energy Res 39:336-343

31. La Mantia F, Huggins RA (2013) Oxidation process on conducting carbon additives for lithium-ion batteries. J Appl Electrochem 43:1-7

32. Yu G, Xie X, Pan L, Bao Z, Cui Y (2013) Hybrid nanostructured materials for high-performance electrochemical capacitors. Nano Energy 2:213-234

33. Śliwak A, Gryglewicz G (2014) High-voltage asymmetric supercapacitors based on carbon and manganese oxide/oxidized carbon nanofiber composite electrodes. Energy Technol 2:819-824

34. Noked M, Okashy S, Zimrin T, Aurbach D (2012) Composite carbon nanotube/carbon electrodes for electrical double-layer super capacitors. Angew Chem Int Ed 51:1568-1571

35. Sivakkumar SR, Pandolfo AG (2014) Carbon nanotubes/amorphous carbon composites as high-power negative electrodes in lithium ion capacitors. J Appl Electrochem 44:105-113

36. Al-Saleh MH, Sundararaj U (2009) A review of vapour grown carbon nanofibers/polymer conductive composites. Carbon 47: $2-22$
37. Muradov N (2001) Hydrogen via methane decomposition: an application for decarbonization of fossil fuels. Int J Hydrogen Energy 26:1165-1175

38. Romero A, Garrido A, Nieto-Márquez A, de la Osa AR, de Lucas A, Valverde JL (2007) The influence of operating conditions on the growth of carbon nanofibers on carbon nanofiber-supported nickel catalysts. Appl Catal A 319:246-258

39. De Yong KP, Geus JW (2000) Carbon nanofibers: catalytic synthesis and applications. Catal Rev 42:481-510

40. Martin-Gullon I, Vera J, Conesa JA, González JL, Merino C (2006) Differences between carbon nanofibers produced using $\mathrm{Fe}$ and $\mathrm{Ni}$ catalysts in a floating catalyst reactor. Carbon 44: $1572-1580$

41. Yu Z, Chen D, Rønning M, Tøtdal B, Vrålstad T, Ochoa-Fernández E, Holmen A (2008) Large-scale synthesis of carbon nanofibers on Ni-Fe-Al hydrotalcite derived catalysts. Appl Catal A 338:147-158

42. Zhou JH, Sui ZJ, Li P, Chen D, Dai YC, Yuan WK (2006) Structural characterization of carbon nanofibers formed from different carbon-containing gases. Carbon 44:3255-3262

43. Ramos A, Cameán I, García AB (2013) Graphitization thermal treatment of carbon nanofibers. Carbon 59:2-32

44. Kavian R, Vicenzo A, Bestetti M (2011) Growth of carbon nanotubes on aluminium foil for supercapacitors electrodes. J Mater Sci 46:1487-1493. doi:10.1007/s10853-010-4950-1 